\title{
Characteristics and the recovery potential of plastic wastes obtained from landfill mining
}

\author{
Chuanbin Zhou*, Wenjun Fang, Wanying Xu, Aixin Cao, Rusong Wang \\ State Key Laboratory of Urban and Region Ecology, Research Center for Eco-Environmental Science, Chinese Academy of Sciences, Beijing 100085, China
}

\section{A R T I C L E I N F O}

\section{Article history:}

Received 16 March 2014

Received in revised form

24 April 2014

Accepted 26 May 2014

Available online 7 June 2014

\section{Keywords:}

Plastic waste

Plastic bag

Landfill mining

Characteristics

Recovery potential

\begin{abstract}
A B S T R A C T
Plastics have been the most consumed materials of human societies in recent decades and, in the mean time, one of the major products obtained from landfill mining. Characteristics of the landfill mined plastic wastes and their recovery potential were the key points to determine the feasibility of landfill mining projects. We collected municipal solid waste samples of different storage years from the landfill and did mechanical screening and manual separating to sort out plastic wastes, and a typical old landfill, which is of 24 storage years and located in central China, was taken as our studied case. According to our research, plastic wastes accounted for $10.62 \pm 5.12 \%$ of the total stored wastes in the old landfill, among which, $69.13 \%$ was plastic bags (white PE plastic bags accounted for $11.34 \%$; colored PE plastic bags 29.77\%; other plastic bags $28.02 \%$ ), and $30.87 \%$ was other plastics (incl. PP, PVC, PS, etc.). The average moisture content in the plastic waste was $19.96 \pm 4.65 \%$ and the average impurities content was $71.02 \pm 6.31 \%$ before manual washing and cleaning. The VS, ash, fixed carbon and calorific value of manually cleaned plastic wastes were $87.09 \pm 0.55 \%, 10.84 \pm 1.19 \%, 2.07 \pm 0.85 \%$ and $43.18 \pm 1.49 \mathrm{MJ} \mathrm{kg}^{-1}$, respectively. Elements testing $(\mathrm{C}, \mathrm{N}, \mathrm{O}, \mathrm{S}, \mathrm{Cl}, \mathrm{Si}, \mathrm{Al})$ and surface images analysis under scanning electron microscope showed that normal cleaning techniques had a difficulty in thoroughly getting rid of all the impurities on the surface of plastic bags excavated from old landfill, which will impede plastic wastes from being mechanical recycled as renewable materials or being chemically recycled by either pyrolysis, gasification, hydrogenation. Incineration or treating as residue derived fuels (RDFs) for recovering energy was the most practical way to process landfill mining plastic wastes under the normal cleaning techniques.
\end{abstract}

() 2014 Elsevier Ltd. All rights reserved.

\section{Introduction}

Human beings explored uncountable mineral products and other natural resources from the ecosystem to produce consumer goods and construct infrastructures, in the mean time, disposed various wastes and stored them in landfills, which have formed socalled urban stocks (Krook, 2010; Krook and Baas, 2013). Statistics showed that around three billion ton municipal solid wastes produced in recent 30 years were disposed in landfills in China (MOHURD, 2012). It is not only a serious occupation of valuable urban lands, but also bury the recyclable materials underground without making use of it. Plastic, which is synthesized using nonrenewable fossil resources, is one of the major consumer goods of human society, largely used in urban life and production, including

\footnotetext{
* Corresponding author. Tel.: +86 1062849147.

E-mail address: cbzhou@rcees.ac.cn (C. Zhou).
}

agriculture, commodities, construction industry, manufacturing industry, packaging, etc, therefore, a great amount of plastic wastes were discharged and disposed in the landfills (Zhang et al., 2007; Al-Salem et al., 2009). "Landfill mining" was put forward under the concept "sustainable material management", which merge the ideas of "urban solid waste management" and "material cycle" together (Krook, 2010; Krook et al., 2012). Landfill mining proposes a feasible approach that excavating the stored wastes out of the old landfills, recycling waste materials, recovering the wastes with high calorie and reclaiming the land and airspace, and landfill mining has been drawing a lot of attention in recent years (Jain et al., 2012; Johansson et al., 2013; Krook and Baas, 2013).

Plastic waste is one of the major products harvested from land mining. According to recent researches, the municipal solid waste stored in landfills normally consists of $20-30 \%$ combustible materials (the primary component is plastic wastes), 50-60\% soil-type materials, $10 \%$ inorganic substances (mainly including concrete, stones and glass) and a small percentage of metals (Cossu et al., 
1995; Zhao et al., 2007; Prechthai et al., 2008; Kaartinen et al., 2013: Quaghebeur et al., 2013). After the stored waste being excavated and screened from the old landfill, metals and construction wastes can be easily recycled, soil-type materials can be applied to green spaces and gardens as fertilizers (Jones et al., 2013), but how to recover more energy from the plastic wastes in landfill mining were still in discussing (Bosmans et al., 2013), and the potential of recovering plastic wastes is the major factor to assess the economic feasibility of a landfill mining project (van der Zee et al., 2004; van Passel et al., 2013). Theoretically speaking, there are four routes of plastic wastes treatment: primary (re-extrusion), secondary (mechanical), tertiary (chemical) and quaternary (energy recovery) (AlSalem et al., 2009). Plastic wastes can either serve as raw material for producing renewable plastic, or be chemical cracked up to oil, carbon coke, $\mathrm{CH}_{4}, \mathrm{H}_{2}$, $\mathrm{CO}$ and other combustible gases, including pyrolysis, gasification, hydrogen pyrolysis, etc, the oils could be recycled as feedstock to petrochemical plants (Al-Salem et al., 2009). Chemical recycling has the advantages of treating heterogeneous and contaminated polymers with limited use of pretreatment for household recycled plastic wastes (Scheirs, 1998; Al-Salem et al., 2009; Bosmans et al., 2013). In addition, plastic wastes can serve as raw material for producing waste derived fuels (RDFs) and also can be incinerated to recover the thermal energy to generate electricity (Al-Salem et al., 2009). Currently, many researches focused on the technologies to recover energy from the plastic wastes (always mixing with paper wastes and wood wastes) in the field of landfill mining (Bosmans et al., 2013; Chiemchaisri et al., 2010).

The plastic wastes in the landfills have experienced long-term physical, chemical and biological reaction processes, which might have different characteristics from those plastic wastes collected from households and industries. Although some researches had focused on the energy recovery approaches of landfill mining currently, to do further studies on the components and physicochemical characteristics of plastics wastes can provide new scientific parameters for assessing the feasibility of resource recycling or energy recovering of landfill mined plastic wastes. A typical old landfill, which closed nine years ago and had twenty-four years of disposal municipal solid waste, was taken as our studied case. The goal of this paper is to assess the recovery potential of landfill mining plastic wastes basing on the analysis on its components and characteristics.

\section{Materials and methods}

\subsection{Description of the studied case}

The Yingchun municipal solid waste landfill site in our case study is located in Jingmen, Hubei Province, central China. The landfill site was constructed in 1989 and closed in 2004, having served for 0.4 million inhabitants. It is a basic, unsanitary landfill and covers an area of $11.3 \mathrm{ha}$. Yingchun landfill was constructed in a small valley, the landform of the original site was low in north and high in south, and the thickness of landfill layers was different. The annual amount of disposed municipal solid waste increased from 36.5 thousand tons in 1989 to 154.8 thousand tons in 2004; the total stored solid waste at the site has been estimated to be around 501,000 tons $\left(551,000 \mathrm{~m}^{3}\right)$. Currently, this site produces around $80 \mathrm{~m}^{3}$ of waste leachate per day, accompanied by uncontrolled emissions of landfill gases.

\subsection{Sampling methods}

Sampling and analyzing methods were shown in Fig. 1. Nine sampling locations were determined following grid sampling

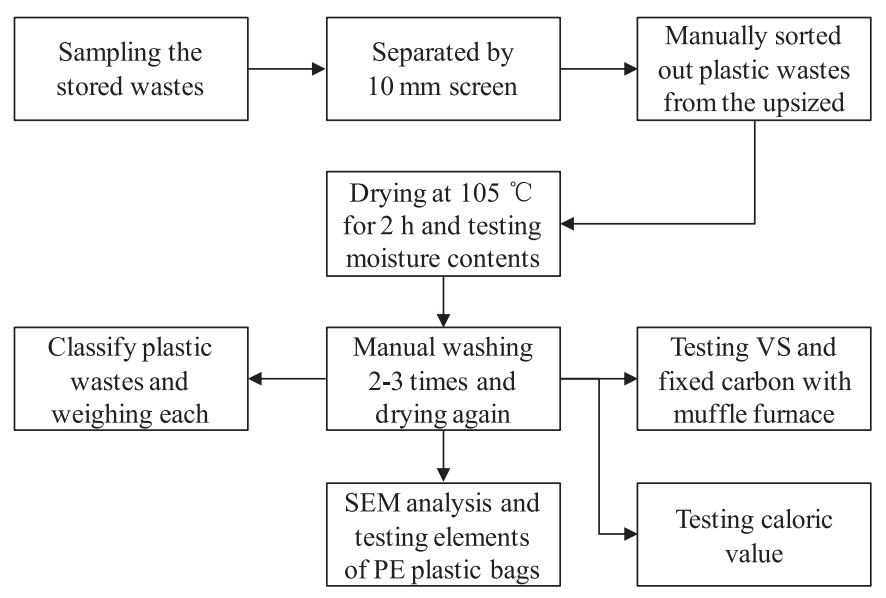

Fig. 1. The sampling and analyzing methods of landfill mining plastic wastes.

method (100 $\mathrm{m} \times 100 \mathrm{~m}$ ), and a drilling machine (with a $\Phi 12 \mathrm{~cm}$ sampling head) was used for sampling stored wastes in Yingchun landfill, and sampling was ongoing from June 18th to June 22nd in 2012. Firstly, we removed about $50 \mathrm{~cm}$ covering natural soils which was used for landfill closure, and sampling was started when the stored wastes (black materials) was detected. And then we sampled the stored wastes for every $6 \mathrm{~m}$, and sampling was ended when the bottom clay (yellow or gray) was detected. The number of obtained samples in each sampling location was not the same (maximum four samples in one sampling location, minimum one sample in one sampling location), because Yingchun landfill was constructed in a small valley, the landform of the original site was low in north and high in south, and the thickness of landfill layers was different for each sampling location. In total, twenty-two samples were collected from different landfill layers: the first layer $(0-6 \mathrm{~m}, 9$ samples), the second layer (6-12 m, 7 samples), the third layer (12-18 m, 4 samples) and the fourth layer (18-24 m, 2 samples), and for each sample weighing around $50 \mathrm{~kg}$. According to historical data of the landfill, the first to the fourth layer of the solid waste were generated from wastes disposed in the years of 2001-2004, 1997-2000, 1993-1996, and 1989-1992, respectively. Each sample of stored wastes was firstly fully mixed, quartered twice or thrice on a plastic cloth to reduce the weight of each sample to about $5 \mathrm{~kg}$.

In the practice of landfill mining and materials separation, stored waste firstly goes through a set of multilevel rotary screen and then a set of vibrating screen. After being screened, the upsized part will go through a winnowing facility (air separation) where the light stuff is sorted out, which primarily consists of polyethylene $(\mathrm{PE})$, polyethylene terephthalate (PET), PolyVinyl Chloride (PVC), Polyurethane (PU) and other plastic materials. Similar to real landfill mining, the stored wastes were separated through a $\Phi 10 \mathrm{~mm}$ screen, and then we manually sorted out the plastic materials from the upsized part got from the stored wastes. The plastic wastes were sent into the laboratory for further analyzing the components and their physicochemical characteristics.

\subsection{Analysis techniques}

We put $150 \mathrm{~g}$ of plastic wastes into a drying oven with the temperature set at $105{ }^{\circ} \mathrm{C}$ and kept it there for $2 \mathrm{~h}$ to test the percentage of moisture content. Then we immersed the dried plastic waste from the oven in a $30 \mathrm{~cm} \times 9 \mathrm{~cm}$ container full of clean water for $10 \mathrm{~min}$ to get rid of the remaining impurities. After that, we added $30 \mathrm{~g}$ of washing powder to the water and kneaded the plastic waste to further clean it 2-3 times. Lastly, we rinsed it completely and then put it into the drying oven again and weighed it again to 
find out the percentage of the impurities on the plastic waste. After cleaning and drying the plastic wastes, we manually classified it into 4 groups, namely, white PE plastic bags, colored PE plastic bags, other plastic bags (synthesized by PET, PVC, PE, etc., some plastic bags had aluminum film) and other plastic wastes (including bottle caps, woven bags and packaging ropes and etc.). This category of sorting plastic wastes was following the investigation of recycling markets in China, the recycling value of this four types of plastic wastes was significant different (recycling value: white PE plastic bag $>$ colored PE plastic bag $>$ other plastic bag $>$ other mixed plastics). Then we weighed different types of plastic wastes of each group to find out the percentage it accounted for.

After that, we put around $10 \mathrm{~g}$ of plastic wastes of each landfill layer into a muffle furnace with the temperature set at $600 \pm 10^{\circ} \mathrm{C}$ to incinerate for $40 \mathrm{~min}$ in order to find out the percentage of ash content. Then, we put around $10 \mathrm{~g}$ of sample into a crucible with a cover and put the crucible in a muffle furnace with the temperature set at $600{ }^{\circ} \mathrm{C}$ and kept it there for $7 \mathrm{~min}$ to find out the percentage of volatile content (VS) and fixed carbon. We used an embedded calorimeter (Model ZDHW-90; Made in Hebi, China) to measure the higher caloric value of the dry basis of the samples. And then we cut the plastic waste samples into 5-10 mm fragments and took five fragments from each group in terms of the type (white PE plastic bag, colored PE plastic bag and other plastic bag). We used a field emission scanning electron microscope (Model SU-8020, produced by Hitachi, Japan) to measure the contents of C, N, O, S, Cl Si, Al and recorded the $2000 \times$ magnification surface images of the plastic waste fragments. We also compared the landfill mined plastic bags and the normal plastic bags and tried to find the differences, the thickness of normal plastic bags was around $0.01-0.02 \mathrm{~mm}$. The white plastic bags were chosen to minimize the impacts on the elements contents by the colored dyestuff. Each testing groups had five replications.

\subsection{Statistical analysis}

All statistical analysis were performed using SPSS version 16.0 for Windows. A one-way analysis of variance (ANOVA), followed by LSD and Duncan test, was used to analyze the moisture contents, impurities contents, VS, ash, fixed carbon and calorie value. An independent-samples $T$ test was used to analyze the elements contents of $\mathrm{C}, \mathrm{N}, \mathrm{O}, \mathrm{S}, \mathrm{Cl} \mathrm{Si}, \mathrm{Al}$. The significant difference was considered at $p<0.05$.

\section{Results and discussions}

\subsection{Components of plastic wastes}

\subsubsection{Percentage of plastic wastes in stored wastes}

In the 22 samples of stored solid waste, plastic wastes accounted for $10.62 \pm 5.12 \%$ on average, ranging from $2.95 \%$ to $21.76 \%$ (see Fig. 2), and $63.6 \%$ of the samples contained more than $10 \%$ of plastic wastes. The samples with the highest percentage of plastic waste was from the first and second layer (dumped from 1997 to 2004), and was significant higher $(p<0.05)$ than from the third layer (dumped from 1993 to 1996). It was probably resulted from the fact that residents started to use more and more plastic products after 1997, especially plastic bags. Researches showed that quantity of plastics consumed in China has been rapidly increasing year after year, up from $10 \mathrm{Mt}$ in 1995 to $26.8 \mathrm{Mt}$ in 2003, tripling the figure in 1995. However, the recycled plastic was only $6 \mathrm{Mt}$ (in 2003), merely $22.4 \%$ of the total consumed plastic in that year (Liao, 2004). In China, plastic products are largely used in manufacturing, construction industry, agricultural film, commodities and packaging industry, especially in packaging industry, which including carry

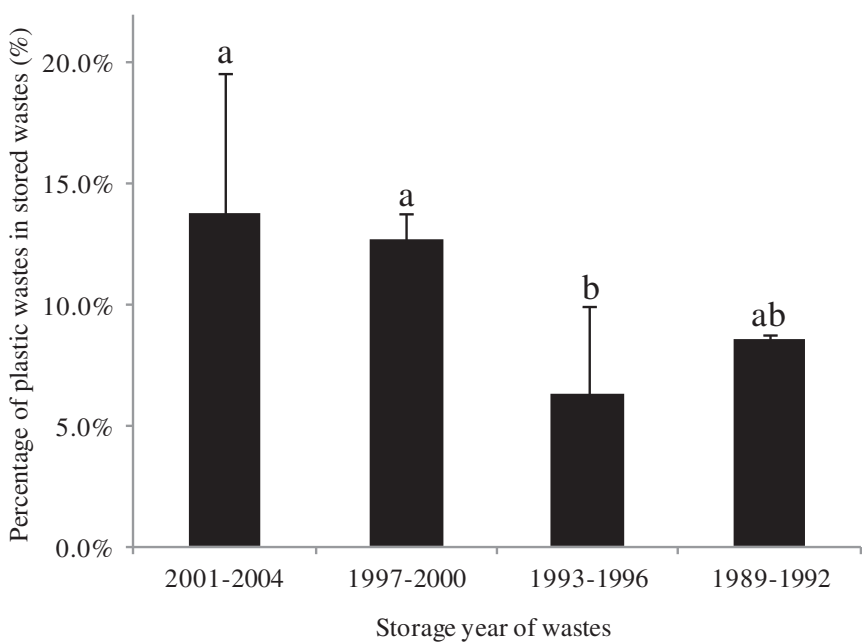

Fig. 2. Percentage of plastic wastes under different storage years. Symbols (a-b) indicate statistically significant difference $(p<0.05, n=22)$.

bags and various films and etc., accounts for $34 \%$ of the total usage (Liao, 2004; Zhang et al., 2007). Moreover, the reports on the components of the municipal solid waste from Yingchun landfill showed that, the percentage (wet weight) of plastic waste went from $0.95 \%$ in 1989 when it first came into service to $3.48 \%$ in 2004 when it was closed, around 3.7 times as much as that in 1989, and the plastics became the most commonly seen wastes at landfill sites. That could explains why the first and second layer of stored waste tops the list in terms of the percentage of plastic waste.

\subsubsection{Moisture and impurities}

Moisture contents of excavated plastic wastes of different storage years are shown in Fig. 3. The average moisture content was $19.96 \pm 4.65 \%$, ranging from $11.66 \%$ to $27.58 \%$, with a significant higher value falling on the second layer (dumped from 1997 to 2000) and similar moisture content values in the first layer and the fourth layer, as well as the lowest moisture content value (only 13.16\%) falling on the third layer. The moisture content in plastic waste is largely associated with the amount of precipitation, the movement of the water in the waste piles, and the biological decomposition of organic wastes. The field sampling time was June, 2012, right before continuous rainfalls in May, which may explains

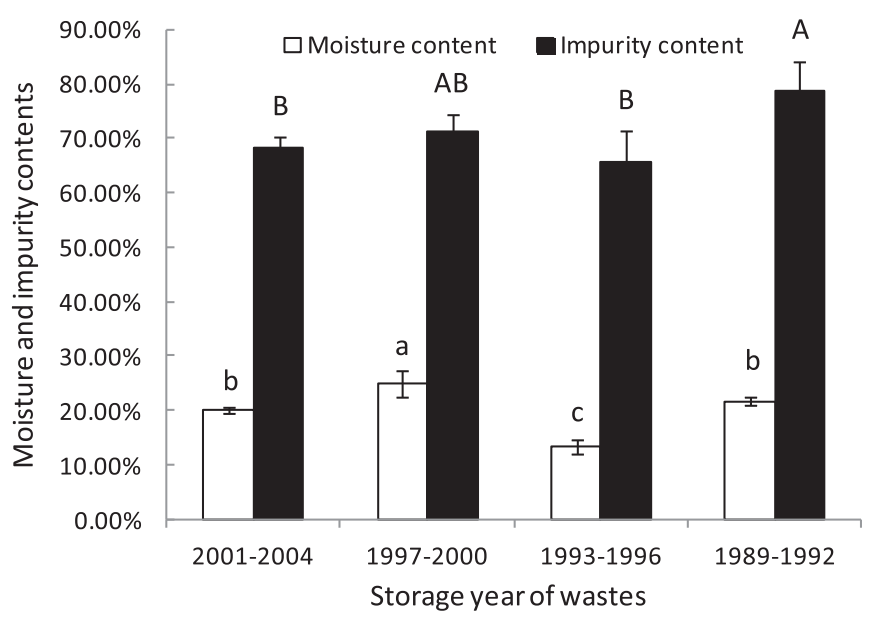

Fig. 3. Moisture and impurity contents of landfill mined plastic wastes under different storage years. Symbols $(a-c, A-B)$ indicate statistically significant difference $(p<0.05$, $n=22)$. 




Fig. 4. Constituents of landfill mined plastic wastes under different storage years.

why the moisture content in the second layer is higher than in the first and third layers if the vertical penetrating of water in the piles was taken into consideration.

Impurities contents of excavated plastic wastes of different storage years are shown in Fig. 3. The impurities content on the plastic waste was relatively high with an average value of $71.02 \pm 6.31 \%$, ranging from $61.78 \%$ to $84.38 \%$, with a significant higher value falling on the fourth layer (dumped from 1989 to 1992) than on the first and third layers. The impurities on plastic wastes may primarily consist of soil-type fractions, sands, waste papers, while plastic wastes primarily consist of various film-type plastic bags, which are light in weight with big surface and therefore good carriers for the impurities (Chiemchaisri et al., 2010; Quaghebeur et al., 2013). The plastic wastes on the fourth layer have experienced biochemical reaction processes for the longest time, and in the mean time, bares the biggest pressure from the upper layer, which probably is the reason that it carries more impurities than those in other layers. Quaghebeur et al. (2013) found that the ash content of plastic fraction in landfills were $20-35 \%$, much higher than normal plastics (1\%), and the sticking dust or sand influenced the measurements. However, in our research, the result of impurities content cleaned by washing process could well support the obvious researches.

\subsubsection{Constituents of plastic wastes}

All the plastic samples were cleaned and classified into 4 groups, namely white PE plastic bag, colored PE plastic bag, other plastic bag and other mixed plastics, and the percentage of each type of plastic wastes was measured. White PE plastic bag, colored PE plastic bag, other plastic bag and other mixed plastics accounted for $11.34 \%, 29.77 \%, 28.02 \%$, and $30.87 \%$, respectively. The percentage of waste plastic bags was up to $69.13 \%$, which is the major component of the plastic wastes excavated from the landfill (see Fig. 4). Plastic carry bags also found to be the main component (38.1\%) among all types of plastic wastes from landfills (Chiemchaisri et al., 2010). In China, the plastic recycling systems of plastic bottles, foam-type plastic, plastic take-away containers, plastic pipes and other plastic materials were functioned better than the waste plastic bags, because waste plastic bags are difficult to be collected and its recycling value is the lowest and therefore becomes the major plastic wastes disposed at the landfills. We barely found plastic bottles (PET) while sampling, which type is of the highest recycling value in China, and this is due to the fact that the Yingchun landfill site was open to rubbish-collectors before it was closed in 2004.

In terms of the storage years, we found that the percentage of waste plastic bags from the layers after 1997 is higher than that from the layers earlier than that year, which resulted from the fact that the production and consumption of plastic bags has been rapidly rising since 1997 and consequently led to more waste and disposal (Zhang et al., 2007). To recycle white PE plastic bags, colored PE plastic bags, other plastic bags (PET/PVC/PE) and other mixed plastic wastes need to classify them first, however, the hydrocyclones was had to applied for separating different plastic wastes because their density are so close to each other $\left(\rho_{\mathrm{MDPE}}=0.941, \rho_{\mathrm{MDPE}}=0.926-0.940, \rho_{\mathrm{LDPE}}=0.915-0.925\right.$, $\rho_{\text {LLDPE }}=0.91-0.94 \mathrm{~g} / \mathrm{cc}$ ) (Zia et al., 2007), and the impurities on the waste plastics also increased the difficulty for density separation method.

\subsection{Physicochemical characteristics of plastic wastes}

\subsubsection{Combustion characteristics}

Average VS, ash, fixed carbon, calorific value of the plastic wastes were $87.09 \pm 0.55 \%, 10.84 \pm 1.19 \%, 2.07 \pm 0.85 \%$ and $43.18 \pm 1.49 \mathrm{MJ} \mathrm{kg}^{-1}$, ranging from 86.31 to $87.50 \%, 9.70-12.50 \%$, $1.19-3.21 \%, 41.29-44.75 \mathrm{MJ} \mathrm{kg}^{-1}$, respectively (see Table 1). The highest VS was in the second layer, while the highest fixed carbon and the calorific value were in the first layer. VS, fixed carbon and calorific value of the plastic wastes were not significantly different according to different landfill layers, but the ash content of plastic wastes in the fourth layer was $12.50 \pm 0.93 \%$, which was significantly higher than other layers $(p<0.05)$.

As for normal plastic waste (PE) without being landfilled for a long time, on average, the VS content is $98.5 \%$, the ash content $1.2 \%$, the fixed carbon less than $0.1 \%$ and the calorific value $43.55 \mathrm{MJ} \mathrm{kg}^{-1}$ (Tchobanoglous et al., 2000). Comparing to our results, the calorific value is similar, the VS content lower, the ash content and fixed carbon both higher. It probably resulted from the fact that the plastic wastes have experienced long-term physicochemical reaction processes, which adhered a lot of impurities (sand, clay and etc.) tightly sticking to the plastic waste and they were consequently very difficult to clean off. One possibility was that the upper-placed waste acted a pressure on the lower-placed one, which the force made the fine sand and soil and other impurities get embedded into the plastic waste. Another possibility was that organic wastes produced a lot of organic acid during anaerobic digestion in the piles. The $\mathrm{pH}$ value appeared acidic in a long period with the lowest point down to 1.5 , which could lead to an even

Table 1

Chemical characteristics of landfill mined plastic wastes of different storage years. Symbols (a-b) indicate statistically significant difference ( $p<0.05)$.

\begin{tabular}{|c|c|c|c|c|c|}
\hline \multirow[t]{2}{*}{ Parameter } & \multicolumn{5}{|c|}{ Storage year of wastes } \\
\hline & $2001-2004$ & 1997-2000 & 1993-1996 & 1989-1992 & Average \\
\hline VS (\% dry weight) & $87.09 \pm 1.09$ & $87.50 \pm 0.48$ & $87.44 \pm 0.52$ & $86.31 \pm 3.23$ & $87.09 \pm 0.55$ \\
\hline Ash (\% dry weight) & $9.70 \pm 0.75^{\mathrm{b}}$ & $10.39 \pm 0.26^{\mathrm{b}}$ & $10.76 \pm 0.48^{\mathrm{b}}$ & $12.50 \pm 0.93^{\mathrm{a}}$ & $10.84 \pm 1.19$ \\
\hline Fixed carbon (\% dry weight) & $3.21 \pm 1.84$ & $2.10 \pm 0.40$ & $1.79 \pm 0.76$ & $1.19 \pm 2.36$ & $2.07 \pm 0.85$ \\
\hline Calorific value (MJ kg-1) & $44.75 \pm 1.18$ & $43.91 \pm 2.17$ & $42.79 \pm 3.10$ & $41.29 \pm 2.26$ & $43.18 \pm 1.49$ \\
\hline
\end{tabular}


closer combination of the impurities and the plastic (El-Fadel et al., 2002). As we know, the ash content in sand and soil (around $68 \%$ on average) is significantly higher than in plastic wastes, while the VS is significantly lower than in plastic waste. All above mentioned
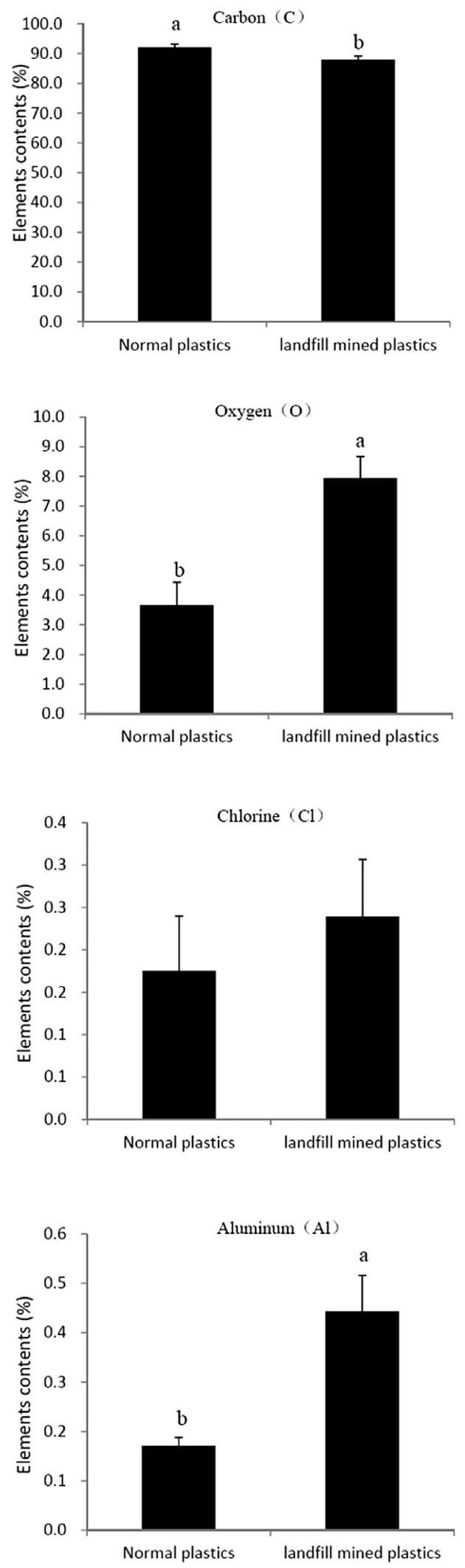

factors might explain the significant difference between typical normal plastic waste and the one from landfill mining, which even had been washed under normal cleaning method (mentioned in chapter 2.3).
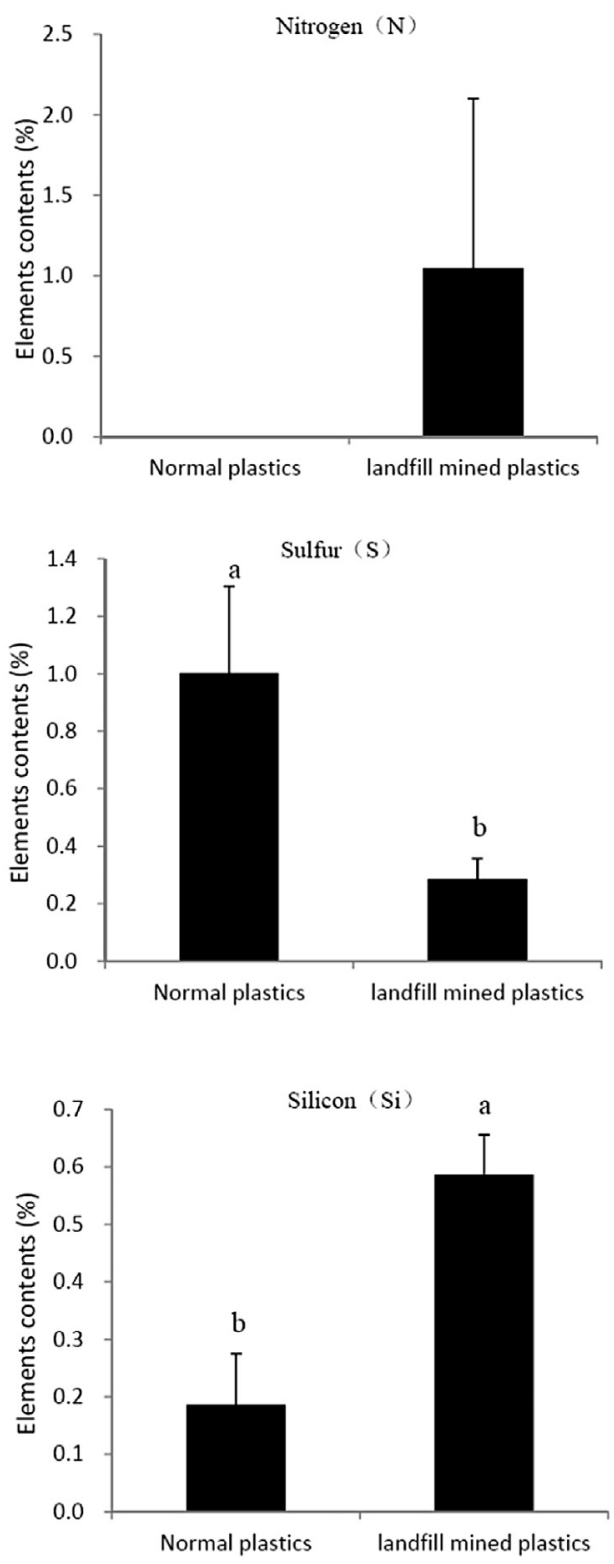

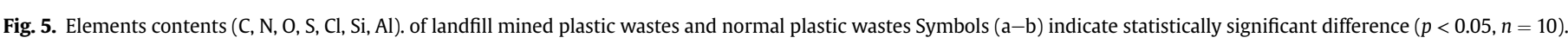



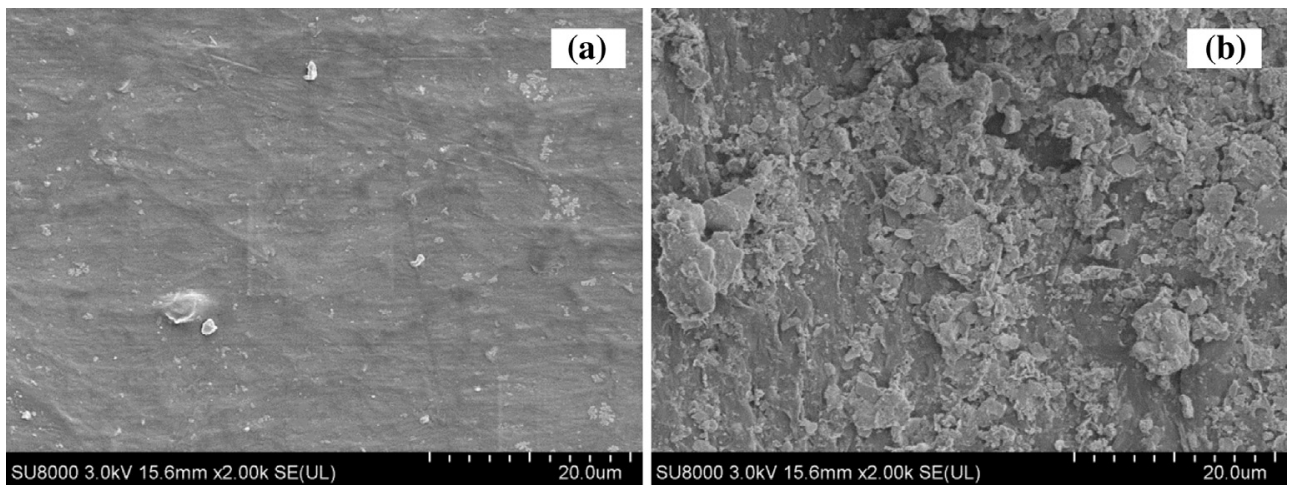

Fig. 6. Surface images of normal plastic waste and landfill mined plastic waste under scanning electron microscope $(2000 \times)$.

\subsubsection{Elements contents}

In order to find out the elementary difference between normal plastic wastes and the plastic wastes mined from the landfill, the content of carbon, nitrogen, oxygen, sulfur, chlorine, silicon and aluminum in white PE plastic bags were tested (see Fig. 5). The average contents of carbon, nitrogen, oxygen, sulfur, chlorine, silicon and aluminum in the landfill mined plastic wastes were $87.955 \pm 1.236 \%, 1.045 \pm 1.055 \%, 7.953 \pm 0.714 \%, 0.286 \pm 0.068 \%$, $0.586 \pm 0.070 \%, 0.443 \pm 0.073 \%$, respectively; ranging from 86.280 to $89.162 \%, \quad 0.000-2.280 \%, \quad 6.929-8.515 \%, \quad 0.206-0.379 \%$, $0.208-0.312 \%, 0.509-0.672 \%$ and $0.377-0.508 \%$, respectively While the average contents of carbon, nitrogen, oxygen, sulfur, chlorine, silicon and aluminum in the normal plastic wastes were $92.092 \pm 1.082 \%, \mathrm{~N} / \mathrm{A}, 3.666 \pm 0.773 \%, \quad 1.003 \pm 0.301 \%$, $0.175 \pm 0.064 \%, 0.186 \pm 0.088 \%, 0.171 \pm 0.017 \%$ respectively; ranging from 90.314 to $93.018 \%, \mathrm{~N} / \mathrm{A}, 2.647-4.445 \%, 0.690-1.496 \%$, $0.115-0.270 \%, \quad 0.107-0.338 \%, \quad 0.150-0.188 \%$, respectively. Compared to normal plastic wastes, the landfill mined plastic waste appears significant lower content of carbon and sulfur but higher content of oxygen, silicon, aluminum, and similar content of nitrogen and chlorine $(p<0.05)$.

Compared to normal plastic wastes, the plastic waste mined from the landfill site appears more impurities that are difficult to clean off, especially small particles of soils and sands, which tops the list for the major components of stored wastes in old landfills. The major constituent of sand is $\mathrm{SiO}_{2}$ and the major constituents of soils are $\mathrm{SiO}_{2}, \mathrm{Al}_{2} \mathrm{O}_{3}$, oxynitride and etc., whereas normal PE plastics contains very little silicon, aluminum and oxygen. As shown in Fig. 6 (surface images of normal plastic waste and landfill mined plastic waste under scanning electron microscope), there are many particulate matters that have larger molecular weight than normal plastic (particle size ranging from 5 to $60 \mu \mathrm{m}$ ). According to our research, the ash content, impurities and the elements $(\mathrm{O}, \mathrm{Si}, \mathrm{Al})$ had some closing relationships. Ash contents of landfill mined plastic wastes were 9.03 times than normal plastic wastes, and the impurities were $71.02 \pm 6.31 \%$ before cleaning, meanwhile, our test results showed that, the contents of oxygen, silicon, aluminum in the plastic waste mined from the landfill is $2.17-3.80,3.15-7.02$ and 2.60-5.98 times as much as that in normal plastic waste, respectively. It tells us that sand, soil and other impurities will remain on the surface of the plastic wastes and the content of them are much higher than in normal plastic wastes, and some impurities even remaining after manual cleaning.

\subsection{Recovery potentials assessment}

The major ways to recycle plastic wastes are as following, mechanical recycling (making renewable materials), chemical recovery (gasification, pyrolysis, and hydrogenation) and energy recovery (to produce RDF or to directly incinerate it to recover thermal energy), mentioned in a technological hierarchy for recycling plastic wastes (Al-Salem et al., 2009). The input criteria of different recovery technologies for landfill mined plastic wastes were shown in Table 2. The plastic wastes mined from the landfill have experienced long-term physical, chemical and biological reaction processes occurred in the waste piles, therefore their physicochemical structures might have been changed by the joint effects of light, heat, moisture and microorganisms. Polymers could be biodegraded under the mechanism of oxidation or hydrolysis by microorganisms in a very slow process (Shah et al., 2008). Different from normal plastic wastes recycled from the household, industries, supermarkets and etc., the landfill mined plastic waste is higher in content of moisture, impurities (still higher in impurities even after cleaning) and ash. However, what is similar to normal plastic wastes is that the landfill mined plastic wastes remains high in calorific value and has a huge potential of energy recovery. China had an amount of three billion ton of MSW buried in the old landfills, and the energy embedding in the buried plastic waste was calculated as 1.37 billion ton of standard coal (based on the data obtained in the case of Yingchun landfill), which accounted for $38 \%$ of the total annual energy consumption of China (3.62 billion tons of standard coal, year 2012).

Having compared the physicochemical characteristics of the plastic wastes to the input criteria of different recovery technologies, we found that: 1) The average content of plastics (wt\%) of landfill mined plastic wastes was around $85.6 \%$, which was

Table 2

Comparison of the input criteria of different recovery technologies for landfill mined plastic wastes.

\begin{tabular}{|c|c|c|c|c|c|}
\hline Input criteria & Mechanical recycling & Gasification & Pyrolysis & Hydrogenation & Incineration/RDF \\
\hline Particle size (mm) & $\mathrm{N} / \mathrm{A}$ & $<100$ & $1-20$ & $<10$ & $\mathrm{~N} / \mathrm{A}$ \\
\hline Moisture (wt \%) & $<1.0$ & $<1.0$ & $<0.5$ & $<1.0$ & N/A \\
\hline Content of plastic (wt \%) & $>90$ & $>90$ & $>92$ & $>90$ & $\mathrm{~N} / \mathrm{A}$ \\
\hline PVC tolerance (wt \%) & $\mathrm{N} / \mathrm{A}$ & $<10$ & $<2$ & $<4$ & $\mathrm{~N} / \mathrm{A}$ \\
\hline Ash (wt \%) & $\mathrm{N} / \mathrm{A}$ & $<6$ & $<2$ & $<4.5$ & $\mathrm{~N} / \mathrm{A}$ \\
\hline
\end{tabular}

Source: Tukker et al., 1999; Sas, 1994; Al-Salem et al., 2009. 
calculated based on the ash contents (soil: $68 \%$; pure plastic: $1.2 \%$; landfill mined plastics wastes: $10.84 \%$ ). It indicated that the pretreatment processes were essential for both mechanical recycling and chemical recovery of plastic wastes according to the input criteria (content of plastic> 90\%), including preliminary cleaning, drying, cutting to pieces and highly-effective cleaning technique, to reduce the particle size and remove the impurities on the surface. 2) PE bags are the most commonly seen fraction in the landfill minded plastic waste, $41.11 \%$ of the total plastic wastes, to which both pyrolysis and hydrogenation could be applied under a comparatively low PVC tolerance (PVC < 10\%) (Tukker et al., 1999; Sas, 1994; Al-Salem et al., 2009). Thus the density separating method should be applied to sort out PVC from PE bags, PET, PVC, PP and other types of plastics beforehand, but it is not easy in current technology. 3) To produce RDFs or to directly incinerate to recover the thermal energy are more practical regarding the maturity of current technologies. Plastic wastes, straws, saw dusts and other combustibles could mix in certain ratios to make RDFs with high calorific value (Chiemchaisri et al., 2010), and according to the chlorine and sulfur contents of plastic wastes, incineration of plastic wastes mining from old landfill will not generate more harmful gases such as sulfur-dioxide, $\mathrm{HCl}$, dioxin, etc. than normal plastic wastes. According to previous researches, incineration and producing RDFs were also had a comparative lower capital and treating cost than chemical recycling methods (Bosmans et al., 2013).

\section{Conclusion}

Plastic waste is one of the major components of the stored wastes in the old landfills and it primarily consists of waste plastic bags. Both the moisture content and impurities content are relatively high in the plastic waste mined from the landfill. The test for the content of ash, oxygen, silicon and aluminum after manual cleaning showed that normal cleaning technique has a difficulty in cleaning off all the impurities on the surface of the landfill mined plastic wastes. Compared the physicochemical characteristics of the landfill mined plastic wastes to the input criteria on different recovery technologies of plastic wastes, we come to a conclusion that to incinerate or produce RDFs from the landfill mined plastic wastes is the practical way to recover the thermal energy under current technological conditions. Other ways, such as gasification, pyrolysis, hydrogenation and material recycling can only be applied after a series of pre-treatment, such as thoroughly cleaning, drying, cutting and sorting.

\section{Acknowledgment}

This research was financially supported by the National Natural Science Foundation of China $(41201579,71033005)$ and the Key Supporting Project of Ministry of Science and Technology of China (2012BAC13B04). This work was also partially supported by the Environmental Sanitation Agency of Jingmen City. Thanks are also due to Zhenfang Wang, Lina Zou who helped us to complete this research and to the reviewers who helped me to improve the paper.

\section{References}

Al-Salem, S.M., Lettieri, P., Baeyens, J., 2009. Recycling and recovery routes of plastic solid waste (PSW): a review. Waste Manag. 29 (10), 2625-2643.

Bosmans, A., Vanderreydt, I., Geysen, D., Helsen, L., 2013. The crucial role of waste-to-energy technologies in enhanced landfill mining: a technology review. J. Clean. Prod. 55 (1), 10-23.

Chiemchaisri, C., Charnnok, B., Visvanathan, C., 2010. Recovery of plastic wastes from dumpsite as refuse-derived fuel and its utilization in small gasification system. Bioresour. Technol. 101 (5), 1522-1527.

Cossu, R., Motzo, G.M., Laudadio, M., 1995. Preliminary study for a landfill mining project in Sardinia. In: Proceedings Sardinia, Fifth International Landfill Symposium.

El-Fadel, M., Bou-Zeid, E., Chahine, W., Alayli, B., 2002. Temporal variation of leachate quality from pre-sorted and baled municipal solid waste with high organic and moisture content. Waste Manag. 22 (3), 269-282.

Jain, P., Townsend, T., Johnson, P., 2012. Case study of landfill reclamation at a Florida landfill site. Waste Mangement 33 (1), 109-116.

Johansson, N., Krook, J., Eklund, M., Berglund, B., 2013. An integrated review of concepts and initiatives for mining the technosphere: towards a new taxonomy. J. Clean. Prod. 55 (1), 35-44.

Jones, P.T., Geysen, D., Tielemans, Y., Van Passel, S., Pontikes, Y., Blanpain, B. Quaghebeur, M., Hoekstra, N., 2013. Enhanced landfill mining in view of multiple resource recovery: a critical review. J. Clean. Prod. 55 (1), 45-55.

Kaartinen, T., Sormunen, K., Rintala, J., 2013. Case study on sampling, processing and characterization of landfilled municipal solid waste in the view of landfil mining. J. Clean. Prod. 55 (15), 56-66.

Krook, J., 2010. Urban and landfill mining: emerging global perspectives and approaches. J. Clean. Prod. 18 (16-17), 1772-1773.

Krook, J., Svensson, N., Eklund, M., 2012. Landfill mining: a critical review of two decades of research. Waste Manag. 32 (3), 513-520.

Krook, J., Baas, L., 2013. Getting serious about mining the technosphere: a review of recent landfill mining and urban mining research. J. Clean. Prod. 55 (15), $1-9$.

Liao, Z., 2004. Situation of China plastic industry in 2003. China Plast. 18 (6), 1-7 (in Chinese).

MOHURD (Ministry of Housing and Urban-Rural Development of China), 2012 China Urban Construction Statistic Yearbook. China Architecture \& Building Press, Beijing (in Chinese).

Prechthai, T., Padmasri, M., Visvanathan, C., 2008. Quality assessment of mined MSW from an open dumpsite for recycling potential. Resour. Conserv. Recycl. 53 (1), 70-78.

Quaghebeur, M., Laenen, B., Geysen, D., Nielsen, P., Pontikes, Y., Van Gerven, T., Spooren, J., 2013. Characterization of landfilled materials: screening of the enhanced landfill mining potential. J. Clean. Prod. 55 (1), 72-83.

Sas, H.J.W. 1994. Disposal of Municipal Solid Waste: Analysis of Environmental Effects and Cost. Centre for Energy Conservation and Environmental Technology, Delft, Netherlands.

Scheirs, J., 1998. Polymer recycling: science, technology and application, first ed Wiley-Blackwell.

Shah, A.A., Hasan, F., Hameed, A., Ahmed, S., 2008. Biological degradation of plastics: a comprehensive review. Biotechnol. Adv. 26 (3), 246-265.

Tchobanoglous, G., Theisen, H., Vigil, S., 2000. Integrated Solid Waste Management Engineering Principles and Management Issues, First ed. McGraw-Hill, New York.

Tukker, A., de Groot, H., Simons, L., Wiegersma, S., 1999. Chemical Recycling of Plastic Waste: PVC and Other Resins, European Commission, DG III, Final Report, STB-99-55 Final. Delft, the Netherlands.

Van der Zee, D.J., Achterkamp, M.C., de Visser, B.J., 2004. Assessing the market opportunities of landfill mining. Waste Manag. 24 (8), 795-804.

Van Passel, S., Dubois, M., Eyckmans, J., de Gheldere, S., Ang, F., Tom Jones, P., Van Acker, K., 2013. The economics of enhanced landfill mining: private and societal performance drivers. J. Clean. Prod. 55 (1), 92-102.

Zhang, G., Zhu, J., Okuwaki, A., 2007. Prospect and current status of recycling waste plastics and technology for converting them into oil in China. Resour. Conserv. Recycl. 50 (3), 231-239.

Zhao, Y., Song, L., Huang, R., Li, X., 2007. Recycling of aged refuse from a closed landfill. Waste Manag. Res. 25 (2), 130-138.

Zia, K.M., Bhatti, H.N., Bhatti, I.A., 2007. Methods for polyurethane and polyurethane composites, recycling and recovery: a review. React. Funct. Polym. 67 (8), $675-692$. 